\title{
МУЗЫКАЛЬНАЯ КУЛЬТУРА ЛИЧНОСТИ: ОБЗОР ИССЛЕДОВАТЕЛЬСКИХ ПОДХОДОВ
}

\section{MUSICAL CULTURE OF THE INDIVIDUAL: A REVIEW OF RESEARCH APPROACHES \\ S. Dylkova}

Summary: The article summarizes research approaches to understanding the influence of musical art on the formation of musical culture of the individual.

The article analyzes the constituent elements of a person's musical culture: perception, the process of listening to music, the formation of musical intelligence, and the presence or absence of innate musicality. Attention is drawn to the "Mozart effect» and "transference effect» as the ability of music to influence the cognitive and cognitive abilities of a person, to create positive incentives to study and activate creative and creative thinking.

The positive-stimulating effect of music on the mental properties of a person is shown. The author demonstrates the grounds for recognizing the presence of such immanent properties as «musical mind» and "musical intelligence», which guide the choice not only in favor of a particular music (determining the listener's tastes and preferences), but also affect the General social self-realization practice.

Keywords: musical culture of the individual, musical taste, the musical and auditory mind, "Mozart effect» and "transfer effect», musical intelligence.

\author{
Дылькова Светлана Викторовна \\ Директор, МБУДО «Детская школа \\ искусств №6» г. Магнитогорска \\ dylkova@gmail.com
}

Аннотация: Статья обобщает исследовательские подходы к осмыслению влияния музыкального искусства на формирование музыкальной культуры личности.

Анализируются составляющие элементы музыкальной культуры личности: восприятия, процесс слушания музыки, формирование музыкального интеллекта, наличие/отсутствие врожденной музыкальности. Обращается внимание на «эффект Моцарта» и «эффект переноса» как возможности музыки влиять на познавательные и когнитивные способности человека, на создание положительных стимулов к учебе и активизации творческого и креативного мышления. Показано положительно-стимулирующее воздействие музыки на психические свойства человека. Продемонстрированы основания для признания наличие у человека таких имманентных свойств как «музыкальный ум» и «музыкальный интеллект», направляющих его выбор не только в пользу той или иной музыки, (определяющих слушательские вкусы и предпочтения) но и влияющих на общесоциальную самореализационную практику.

Ключевые слова: музыкальная культура личности, музыкальный вкус, музыкальный и слуховой ум, музыкальные способности и музыкальность, «эффект Моцарта» и «эффект переноса», музыкальный интеллект.

\section{$[9,10]$.}

Культурный взрыв, произошедший во всем мире в XX веке создал массовую, всеобщую потребность общения с художественным творчеством, в первую очередь, с разными видами музыкального искусства. Интересно и, отчасти, парадоксально то, что в процессе постоянного рождения новых видов и жанров, стабильно востребованной остается академическая музыкальная классика, истоки которой берут свое начало на рубеже 17-18 веков.

Музыка со времен античности всегда привлекала пристальное внимание мыслителей как важный феномен человеческого сознания и бытия. В процессе дифференциации наук, музыка сохранялась в качестве объекта изучения во многих из них. Известно, что колыбелью современного академического музыкального искусства является Европа. В связи с этим, представляется актуальным обобщение взглядов европейских исследователей (к которым мы относим и российских ученых) на роль музыкальной культуры в формировании личности 
и общества.

Первые шаги в направлении научного исследования психофизиологических возможностей слуха (в контексте восприятия музыки) осуществляются немецким физиологом, психологом и акустиком Германом Гельмгольцем (1821-1894), создавшем «Учение о слуховых ощущениях как физиологической основы для теории музыки» (1862) [4]. Его ученики Вильгельм Вундт (1832 - 1920) и Иван Михайлович Сеченов (1829-1905) закладывают основы самостоятельной экспериментальной науки - психологии, открывая возможности изучения феномена музыкальной трансформации психической жизнедеятельности человека.

Немецкий врач, психофизиолог Фридрих Штейнгаузен (1859-1910) впервые, анализируя исполнительскую деятельность пианистов и скрипачей, обращает внимание на то, что в основе музыкального творчества лежат психофизиологические процессы (1903 г. - «Физиология ведения смычка», 1909 г. - «Техника игры на фортепиано») [13]. В это же время немецкий музыковед и композитор Герман Кречмар (1848-1925) создает учение о музыкальной герменевтике (1902), возродив поиски истолкования содержания музыки в теориях музыкальной риторики и теории аффектов 17-18 веков (Р. Декарт, И. Маттезон, Ф.В. Марпург и др.).

Немецкий пианист, музыковед и музыкальный педагог Карл Мартинсен (1881-1955) своим этапным исследованием «Индивидуальная фортепианная техника» (1930) ставит во главу музыкального творчества такие психологические установки, как «звукотворческая воля», «ритмо-воля», «линиеволя», «воля к форме» (по аналогии с философским трудом Артура Шопенгауэра (1788-1860) «Мир как воля и представление» (1818), где искусству и музыке отводится важное место [8]).

Вслед за тем ряд общественных наук - социология, культурология, этика, эстетика, музыкальная психология, психотерапия уже во второй половине XX века, рассматривают искусство и, прежде всего, музыкальную культуру как важный элемент эффективного образования, интеллектуального развития, культурного просвещения, психического здоровья личности (Т. Адорно, Х. Гембрис, Дж. Дэвидсон, Дж. Слобода, С. Кельш, Х. Бастиан, Р. Шумахер и др.).

Множество концепций развития музыкальной культуры говорит о том, что она является сложной, многоаспектной системой, элементами которой становятся виды музыкальной деятельности, и само музыкальное искусство, оказывающее возвышающее, объединяющее, организующее воздействие на людей.

Одним из элементов этой системы является музыкальный интеллект. Существует мнение французского психолога Ж. Пиаже (1896-1980), что в целом развитый интеллект проявляется в универсальной адаптивности, в достижении «равновесия» индивида со средой. Ж. Пиаже постулирует интеллект как высшую форму духовного приспособления человека к окружающей его среде путем мгновенной организации стабильных пространственно-временных логических структур [5, с. 128]. Это подводит к выводам о том, что:

- существует индивидуальный интеллект, который формирует индивидуальные черты поведения человека;

- на качество индивидуального интеллекта оказывает влияние прослушиваемая (предпочитаемая) его носителем музыка.

Индивидуальный интеллект как сочетание ряда разных независимых способностей описан в книге современного американского психолога Говарда Гарднера (род.в 1943 г.).Веготеории «множественного интеллекта» определены восемь типов интеллекта: лингвистический, логико-математический, визуально-пространственный, музыкальный, экзистенциональный, межличностный, телесно-кинестетический, натуралистический. Одним из основных типов интеллекта назван музыкальный интеллект, как способность к порождению, передаче и пониманию смыслов, связанных со звуками, «интонационных смыслов» (по Б.В. Асафьеву), которые определяются как слуховой ум. Теория Г. Гарднера связывает музыкальный интеллект с другими специальными способностями и стимулирующими их развитие занятиями музыкой [6, с. 194]. Это позволяет ученому говорить об особом «музыкальном интеллекте», в формировании которого участвуют оба полушария головного мозга, а не только «правополушарная» сфера эмоциональных реакций $[7$, c. 40-41].

Исследователи отмечают сложное многоаспектное взаимодействие интуиции, эмоций и интеллекта в музыкальном творчестве и восприятии музыки. Предметом дискуссий западных ученых стал «Эффект Моцарта». Эмпирически подтверждено, что упорядоченная музыка Моцарта является некоей подпиткой мозга для развития пространственно-временного мышления. «Эффект Моцарта» позволяет увидеть благотворное влияние музыки на все стороны обучения ребенка. Обнаружилась ее стимулирующая роль в жизнедеятельности не только человека, но и животных [20]. Впоследствии высказывались мнения, что любая классическая музыка, а не только музыка Моцарта, может стимулировать интеллект и тонус человека. Доктор Ральф Шумахер из Берлинского Университета имени Гумбольдта, в статье «Делает ли музыка Моцарта тебя умным?» рассказывает о активизации формирования познавательных навыков через слушание музыки Моцарта [22, с. 13]. В то же время, Р. Шумахер приходит к выводу, что существует еще целый ряд стимулов, которые положительно влияют на когнитивные 
способности. Это и слушание читаемых вслух рассказов Стивена Кинга, и слушание музыки Баха, Шуберта и даже поп-музыки. При этом когнитивные познавательные процессы усиливаются как при хорошем и благоприятном рациональном впечатлении от прослушанной музыки, так и при разного рода положительных эмоциях, способствующих пробуждению креативных способностей, усвоению нового.

Исследования влияния музыки на активизацию ума представлены в научно-исследовательском сборнике «Делает ли нас музыка действительно умнее?», который включает ряд теоретических и практических статей об экспериментах в детской студии музыкального искусства Германии. Автор и составитель данного сборника Хайнер Гембрис в своей статье «Музыка, интеллект и личностное развитие» определяет музыкальную учебу как трансфер-эффект для реализации личности, воспитывающий в детях интеллект [16, с. 199-212].

Эффект переноса активности музыкальных занятий на восприятие школьных предметов и на формирование ценностных компетенций поднимает Эльке Вуллнер, практикующий дирижер оркестра медных духовых инструментов (Die Österreichische Blasmusikverband). Она в своей квалификационной работе, в рамках семинара австрийского объединения медных духовых инструментов, определяет следующие компетенции, которые развиваются у детей и молодежи в процессе общения с музыкой: социальные ориентации, эстетика и этика общения, интеллект, волевая концентрация. Анализируя детскую педагогику, она говорит о длительном воспитательном процессе, об эмоциональной неустойчивости подростков, о том, что музыка может помочь преодолеть эту неустойчивость и утвердить веру в самого себя $[25$, c. 34].

Особое значение в изучении музыкальной культуры личности отводится музыкальности, как ее основе. Во второй половине 20 века исследования Х. Гембриса [15, с. 17-25] в области музыкальной антропологии выявили историческую и культурологическую вариативность понятия музыкальности как феномена культуры. Ученым было установлено, что характер музыкальности личности, ее структура зависит как от национальных и временных особенностей языка музыки, так и от эстетических принципов конкретной эпохи. В то же время существует внекультурная универсальность базовых слуховых (музыкальных) способностей человека.

Такая концепция коррелируется с языковой (речевой) концепцией американского лингвиста и философа Авраама Ноама Хомского, говорящего о врожденных, генетических задатках речевых мыслительных операций. Стал использоваться этот психолингвистический подход и в музыкальной нейродидактике, когнитивной музыкальной нейронауке. Успешно стало развиваться направление психотерапии с доказательствами неоспоримого положительно-стимулирующего воздействия музыки как на физиологические, так и на психические функции человека. Музыкальный психолог Джон Слобода (Великобритания) ввел понятие «музыкальный ум» человека [23, с. 17-25]. Он пишет, что взаимодействие музыки и сознания можно видеть во всем разнообразии музыкальной деятельности. Изучать феномен музыкальности нужно, так как музыка проявляет себя, оказывая влияние на человеческую личность.

Понятие «музыкальные способности» синонимично понятию «музыкальность». Существует утверждение, что каждый человек музыкален. Это утверждение оппонирует точке зрения о музыкальности как об индивидуальном природном даре отдельных личностей (Б.В. Теплов - «Психология музыкальных способностей», критика европейских исследователей Г. Ревеша и К-Э. Сишора, утверждавших врожденность музыкальных способностей). Научная установка в определении музыкальных способностей, данная отечественным ученым Б.В. Тепловым, указывает, что эти способности определяются только в целенаправленной музыкальной деятельности. Они имеют индивидуальную направленность (определенный музыкальный инструмент, исполнительство, композиция). Они большей частью проявляются неравномерно, имеют кризисное развитие. Существуют потенциальные способности, имеющие разный характер и сочетание высотного, ритмического, ладового, тембрового слышания, разный уровень и направленность музыкальных интересов и привязанностей [11].

В книге немецкого исследователя Кристофа Дроссера есть такое суждение: «Музыкальность - это, скорее всего, такое качество, которым обладает практически каждый из нас... хотя мы все больше слушаем музыку, все меньше мы играем (музицируем)» [14, стр.3]. Он отмечает, что музыкальность кроме специальных музыкальных задатков включает в себя целый ряд свойств и качеств личности: ритмическое чувство, удовольствие от музыкальных упражнений, радость от занятий искусством в школе, удовольствие от музыки в целом. [14, стр.275].

Другим элементом музыкальной культуры личности является формирование музыкальной культуры восприятия.

Воздействие музыки на подсознание человека, на его внутреннюю природу, определяется латентным - интуитивным отношением к музыкальному содержанию, ассоциирующемся с «неявными знаниями» (М. Полани). Как отмечает Г.В. Воронин, «в современной музыкальной системе многовековой слуховой отбор, направленный мелодико-гармоническим инстинктом человека, обеспечил высокую степень ее соответствия какой-то системе внутренних психофизиологических процессов». На этом основании Г.В. Воронин делает вывод: «музыка как-то из- 
начально заложена, скрыта внутри нас, но этого мы не осознаем» [3, с. 609].

Восприятие музыки это всегда событие для человека, который умеет слышать и воспринимать ее (понимать ее язык). Особое значение имеет воспитание музыкой в дошкольном и младенческом возрасте, особенно первые эмоциональные реакции пробуждения на события окружающей звуковой среды. В связи с этим ценным представляются первые музыкальные впечатления, зафиксированные известными композиторами. М. Равель отмечает присутствие уже в своем младенческом возрасте острого интереса к музыкальным звукам: «Будучи маленьким ребенком, я был чувствителен к музыке - к любому виду музыки» [21, с. 23].

Процесс психологии восприятия рассматривает в XX веке (с 1912 года) гештальтпсихология, представленная в трудах немецких ученых М. Вертгеймера, В. Келера, К. Кофки. Основная идея этого научного направления в том, что люди воспринимают окружающий мир в целом, а не его отдельные элементы. Они воспринимают гештальты - завершенные образы. Но целое не равно сумме его отдельных частей. Мозг достраивает услышанное и увиденное глазом, включая ассоциативный, виртуальный ряд. Наследственные интеллектуальные потенции позволяют музыкальному интеллекту развиваться в процессе активного взаимодействия индивидуума и музыкальной среды. Использование этих «неявных знаний» помогает педагогам как пониманию процесса восприятия музыки, так и выработке оптимальных методик обучения музыке.

Проблема восприятия связана с ценностной позицией в отношении прослушиваемой музыки. И хотя, всегда существует субъективное мнение о музыке, определение хорошей, и плохой музыки, правильного и неправильного слушательского вкуса дают относительно объективные ориентиры ценностных оценок в музыкальном искусстве. На основе какого состояния человек отвергает или принимает ту или иную музыку? Изучением проблем эстетического опыта занимается немецкий «Институт эмпирической эстетики», созданный в 2013 году во Франкфурте на Майне [12] на базе Общества научных исследований имени Макса Планка (открывшим квантовую природу света и тесно связанным на протяжении всей жизни с музыкальным искусством). В институте существуют: исследовательская группа «Истории музыки разума и тела», исследовательская группа «Вычислительное слуховое восприятие», исследовательская группа «Нейронные и экологические ритмы». Институт занимается исследованиями, используя метод анкетирования людей, не занимающихся профессионально искусством, или наоборот, занимающимися им по разным специальностям и направлениям. Темами исследований являются характеристики, причины и функции «бракованной» музыки или описание оценки и эффекта вокальной выразительности. Многие исследования посвящены рассмотрению возникающих ассоциативных связей, рождаемых восприятием музыки. Так, глава исследовательской группы «Нейропознание музыки» Стефан Кельш (профессор биологической психологии и психологии музыки в кластере передового опыта «Языки эмоций») изучал нейронные реакции на эмоции радости, горя, страха. В работах 2006 года немецкого ученого проводятся результаты исследования эмоций, рождаемых музыкой [18]. Он использует «приятную» и «неприятную» музыку для того чтобы понять, какое действие на личность вызывает музыка разных жанров. Он проводил исследования с помощью томографа со студентами, которые никогда не играли на музыкальных инструментах и не имели музыкального образования. Исследователь проигрывал им гармонично звучащие аккорды, иногда включая так называемые фальшивые звуки. В эти моменты, у слушателей возбуждались те области мозга, которые отвечают за грамматические ошибки в текстовом предложении. Ошибочные аккорды вызвали нервные импульсы в обоих полушариях. Измерение нейронных потоков мозга (ЭЭГ) подтвердило магниторезонансное изображение (МРТ). Благодаря сканированию мозга с помощью функциональной магнитно-резонансной томографии ученый выяснил, что опыт музыкального удовольствия отражается в трех участках мозга: миндалине, гиппокампе и слуховой коре. Вывод ученого таков: «у нашего мозга есть отдел смыслового значения и структуры музыки, который функционирует по существу также, как при анализе семантики и синтаксиса языка» [17].

Не менее интересными являются исследования о том, какую музыку человек предпочитает слушать. Ученые Германии (Иоганн Мюллер, Стефан Кельш, Хайнер Гембрис), Англии (Диана Омиджи), Соединенных Штатов Америки (Дэвид Гринберг) пришли к выводу, что предпочтение, оказываемое той или иной музыке, соответствует характеру конкретного слушателя. Характер же формирует среда. Британские психологи Питер Джейсон Рентфроу и Сэмюэль Гослинг из Кембрижского Университета определяют поклонников энергичной вокальной музыки как экстравертов, а музыка кантри по их данным характерна для эмоционально устойчивых людей (сангвиников). Любители джаза определялись ими как интеллектуалы. Известно, что искусство является зеркальным отображением жизни. Но все же музыкальный вкус часто определяется не только эпохой, а и личностным впечатлением. К такому выводу приходит Иоганн Мюллер в книге «Вопросы музыкального вкуса» [19, с. 133].

Исследования эстетических вкусов человека при восприятии музыки отражали интерес к этой проблеме уже в 18 веке. Дэвид Юм (1711-1776) пытался определить, как человек оценивает эстетические объекты. Его эмпирическая эстетика развития, открыла путь оценки таких объектов. По Д. Юму человек имеет скрытое внутреннее эстетическое чувство, которое меняется в разные пери- 
оды жизни («Schlüsselerlebnis» - в переводе с немецкого языка «ключевой опыт») определяет изменчивость эстетического восприятия. Сегодня ряд исследований и программ по культуре в Германии поднимают проблему личностного восприятия человека, слушающего разную музыку. В частности одна из статей Хайке Стювела раскрывает тезис, определяющий характер человека и его личностную характеристику: «Скажи, что ты слушаешь, и я скажу кто ты» [24].

Мысль о том, что нам нравится то, что нам уже знакомо, раскрывается в целом ряде исследований о «сознательности вкуса». О сознательности вкуса французский социолог и философ Пьер Бурдье писал в книге «Различение: социальная критика суждения» (1979) [2]. Он говорит о формировании эстетического вкуса при восприятии произведений искусства в связи с базой экономических и культурных различий реципиента. Он определяет художественный вкус как один из продуктов социализации человека. Несмотря на подсознательное мировосприятие и личностный строй эмоциональных жизненных реакций в младенческом возрасте, восприятие в дальнейшем всегда фильтруется через заранее заданные средой интеллектуальные коды, которые перерастают в культивированную способность эмоционально воспринимать и выполнять сложные практические задания. Такое восприятие принадлежит только тем, кто овладел этим языком сложных понятий или кодами. Если культурный код автора и того, кто воспринимает его произведение не совпадает, то у последнего теряется возможность его понять. О таком непонимании говорит Т. Адорно (1903-1969), описывая развлекательный тип слушателя. «Развлекательный тип исторически подготовлен типом потребителя культуры благодаря отсутствию у последнего конкретной связи с объектом, музыка для него не смысловое целое, а источник раздражителей. Здесь играют роль элементы эмоционального и спортивного слушания... Одержимый манией человек находит путь примирения и с ситуацией социального гнета, и с ситуацией своего одиночества тем, что изображает их в определенном смысле как реальность своего собственного существования: известное обращение «Оставьте меня в покое» он превращает в некое иллюзорное царство личного и частного существования, полагая, что в этом царстве он может быть один» [1, с. 23]. Таким образом, музыка выполняет и предназначенную ей особую социальную функцию. «Эти условия коренятся в глубоких слоях общественного устройства, в разделении умственного и физического труда, высокого и низкого искусства, далее - в половинчатом образовании, привившемся в обществе, и наконец, в том, что правильное сознание невозможно в ложном мире, и в том, что способы общественной реакции на музыку следуют за ложным сознанием» [1, с. 25].

Подводя итог можно сделать следующие выводы. Музыкальная культура личности имеет исключительную общественную значимость как база ее полноценной общественной реализации. Музыка выполняет коммуникативную и социальную функции и, в то же время, является психологическим феноменом, отражающим как индивидуальную психику конкретного человека, так и психологию социальных групп.

В работах западно-европейских исследователей культурологическая парадигма исследований музыкальности складывается из двух исследовательских направлений.

Первое связано с определением музыкальной культуры личности как базовой характеристики личностнопсихологических свойств, обусловленных восприятием музыки и формированием музыкальной слушательской культуры. Это музыкальный интеллект, музыкальные способности, музыкальность. Эти качества лежат в основе музыкальной культуры личности и задают уровень слушательской культуры и культуры общения с музыкальным материалом. В многочисленных работах западно-европейских исследователей показано влияние музыки на гармонизацию эмоций, на организацию мышления, на координацию психических состояний человека. Определяется некая индивидуальная музыкальность, которая обозначается как возможность каждой личности приобщиться к музыкальному искусству. Большое внимание уделяется вопросу воздействия музыки и музыкальных занятий на познавательные и когнитивные способности человека, связанные с «эффектом Моцарта», а также на воспитание культурной базы, культурного потенциала для саморазвития личности.

Второе исследовательское направление связано с интерпретацией музыкальной культуры личности как стимулятора любой интеллектуальной деятельности индивида. В этом определяется главная, социальная значимость академического музыкального искусства. Оно становится средством интеллектуального развития не только конкретной личности, но и социума.

В то же время, в процессе общения с музыкой, личность формирует свой характер взаимодействия с ней. Вкус и предпочтения человека могут меняться вместе с изменениями человеческого характера. Музыкальная культура личности связана не только с личностным выбором, но и зависит от социальных и, даже, государственных установок. Один из принципиальных выводов, который можно сделать на основании проведенного анализа, следующий: музыкальный фон, окружающий человека с рождения, влияет на формирование его мышления и качество его интеллектуальной деятельности в дальнейшем. Широкий спектр проблем взаимодействия музыкальной культуры и личности говорит об особой важности и социальной значимости данной культурной составляющей жизнедеятельности социума. 


\section{ЛИТЕРАТУРА}

1. Адорно, Т. Избранное: Социология музыки / Т. Адорно. - Москва-Санкт-Петербург.: Центр гуманитарных инициатив, 2017. - 446 с.

2. Бурдье Пьер Различение : социальная критика суждения /пер.с фр. 0.И. Кирчик // Западная экономическая социология. - М.: Российская политическая энциклопедия, 2004. -680 c.

3. Воронин Г.В. Современная музыкальная система как самоотражение организации бессознательного // Бессознательное: Природа, Функции, Методы исследования: в 4 т. / под общ.ред. и с предисл. А.С. Прангишвили и др. - Тбилиси: Мецниереба, 1978. - Т.2. - С. 607-621.

4. Гельмгольц Г. «Учение о слуховых ощущениях как физиологическая основа для теории музыки: пер.с нем. изд.3-е.- Москва.: Книжный дом «ЛИБРОKOM», 2013. - C. 592

5. Интеллект // Новая философская энциклопедия [Текст] : в 4 т. — Москва : Институт философии РАН, 2010. —-Т.2. — C. $128-277$.

6. Ильин, Е.П. Психология творчества, креативности, одаренности / Е.П.Ильин. — Издательство «Питер», 2011. - 444 с.

7. Как учат музыке за рубежом. - М.: Классика- 21, 2009. -206 c.

8. Мартинсен К. Индивидуальная фортепианная техника / К.Мартинсен. — М.: Музыка, 1966. - 230 с.

9. Синецкий, С.Б. Искусство и интеллектуализация общества: новый старый смысл культурной политики (Начало) [Текст] / С.Б. Синецкий, Т.М. Синецкая // Вестн. Челяб. гос. академии культуры и искусств. - 2014. - № 3(39). - С. 41-45.

10. Синецкий, С.Б. Искусство и интеллектуализация общества: новый старый смысл культурной политики (Окончание) [Текст] / С.Б. Синецкий, Т.М. Синецкая // Вестн. Челяб. гос. академии культуры и искусств. - 2014. - № 4(40). - С. 46-50.

11. Теплов Б.В. Психология музыкальных способностей / Б.В.Теплов. - М.: Планета музыки. - 1953. -488 с.

12. Цифры и факты // Наука и жизнь. - 2013.- № 1. - С. 108.

13. Штейнхаузен Ф. Физиология ведения смычка [Текст]: сокращенный перевод с немецкого издания Марка Мейчика в сотрудничестве с В.Н.Алексеевым (с 36-ю рисунками) / Штейнхаузен. - Москва: Музторг ПТО МОНО, 1930. - С. 108.

14. Drösser Christoph Der Musik-verführer: Warum wir alle musikalisch sind / Ch. Drösser. - Reinberg bei Hamburg: RowohltTaschenbuchVerlag, 2011. — p. 316.

15. Gembris H. Historical phases in the definition of musicality. Psychomusicology: журнал исследований в области музыкального познания, том 16 (1-2), Spr 1997, pp. 17-25

16. Gembris Heiner, Kraemer R.D. Macht Musik wirklich klüger : Musikalisches Lernen und Transfereffekte», band 8, Wisner-verlag, 2006. -p. 154.

17. Hollricher Karin Konzert im Kopf: журнал Bild der Wissenschaft, - 2003. - № 8 - pp. 24-31.

18. Koelsch S., Fritz T, Yves D, Cramon V, Mueller K., Angela D. Friederici Investigating emotion with music: журнал Human Brain Mapping Tom (vol) 27, An fMRI study, $2006,-$ pp. 239-250.

19. Müller J.H. Fragen des musikalischen Geschmacks / J, Müller.- Köln und Opladen: Musik, - 1963. - p. 157.

20. Rauscher F.H., Gordon L. Shaw, Linda J. Levina, Katherine N. Ky. Music und spatial task performance: A. Causal Relationship: Los Angeles: Nature. - 1994. - p. 611.

21. Rolland R. Maurise Ravel: Esguisse biographigue. Paris. - 1928. - p. 150.

22. Schumacher Ralph Macht Mozart schlau? Die Förderung kognitiver Kompetenzen dürch Musik / R. Schumacher.-Bundesministerium für Bildung und Forschung, Berlin. - 2006. - p. 183.

23. Sloboda, J. Musical ability текст /J. Sloboda // The origins and deveiopment of high ability. G. R. Bock, K. Ackrill (eds). - Chichester: Wiley. - 1993, pp. 106-118.

24. Stüvel, Heike : die Zeitung «Welt». - 2007. Электронный ресурc: https://www.welt.de/wissenschaft/artikle1226422/Sage-mir-was-du-hörst-und-ich-sage-dirwie-Du-bist.html.

25. Wullner E. Musika als Begleiter / E. Wullner, Abschlussarbeit Jugendreferentenseminar, 2009. - p. 68.

(c) Дылькова Светлана Викторовна (dylkova@gmail.com) 